\title{
COMPORTAMENTOS E ATIVIDADE DIÁRIA DE SCIURUS INGRAMI (THOMAS) EM CATIVEIRO (RODENTIA, SCIURIDAE) ${ }^{1}$
}

\author{
Marcelo Bordignon ${ }^{2}$ \\ Emygdio L.A. Monteiro Filho ${ }^{2}$
}

\begin{abstract}
BEHAVIOUR AND DIARY aCTIVITY OF SCIURUS INGRAMII (ThOMAS) IN CAPTIVITY (RodenTIA, SCIURIDAE). From October 1994 to November 1995 the behaviour, postures and diurnal activity of five captive squirrels Sciurus ingrami were observed and registered. Four basics postures, five grooming behaviours, displacements and face wiping behaviour were identified. Based on behavioural observations, the diurnal activity was divided into four categories: resting, displacement, feeding and maintenance. The time spent in each category varied seasonally and the squirrels spent more time resting during winter and spring. However, more time was spent feeding during autum and summer and was reduced the displacement in autum. Two types of breeding behaviour were identified: sexual trailing and mating chase of females by males. However copulatori behaviour was not recorded during the studied period. We also verified that $S$. ingrami presents thermorregulation behaviour during winter, remaining resting in the nest to conserve energy in heath maintenance. During the hottest seasons, the squirrels remain resting out of the nest, placed on the branchs to decrease their body heat to normal temperature. The behaviours observed in this study were similar to those described in the literature, as well as the mating behaviour, which was very similar to $S$. carolinensis.
\end{abstract}

KEY WORDS. Sciurus ingrami, sciurids, behaviour, serelepe

De acordo com GuRNell (1987), o número de espécies de esquilos nas florestas tropicais é maior do que os existentes no Hemisfério Norte. Apesar disto, pouco se conhece sobre a maioria dos ciurídeos Neotropicais (EMMONS 1990).

A história natural dos ciurídeos do hemisfério norte, é atualmente bem conhecida (WAUTERS \& DHONDT 1989; Fischer \& Holler 1991; Riege 1991 entre outros) e apesar da maior parte dos trabalhos visarem a populações em liberdade, aspectos do comportamento só puderam ser obtidos através do acompanhamento em cativeiro, como por exemplo o comportamento de aprendizagem na predação de frutos de avelã (EIBL-EIBESFELDT apud TINBERGEN 1966), o estabelecimento de hierarquias sociais (PASITSCHNIAK-ARTS \& BENDELL 1990) e o desenvolvimento do comportamento individual de S. carolinensis (HorwICH 1972).

1) Contribuição número 1005 do Departamento de Zoologia, Universidade Federal do Paraná.

2) Departamento de Zoologia, Universidade Federal do Paraná. Caixa Postal 19020, 81531-990 Curitiba, Paraná, Brasi!. Bolsista do CNPq.

E-mail: bordigno@bio.ufpr.br

E-mail: elamf@bio.ufpr.br. 
Para os ciurídeos brasileiros no entanto, poucos estudos sobre biologia, ecologia e comportamento foram realizados, com exceção de algumas informações sobre alimentação e predação de frutos obtidas para o serelepe Sciurus ingrami (GAlETTI et al. 1992; BORDIGNON et al. 1996). Assim, a inexistência de dados na literatura sobre observações comportamentais e manejo desta espécie, dificulta por vezes, o estudo dos mesmos em vida livre, tendo em vista a falta de conhecimento a respeito de seu comportamento básico, como posturas e atividade diária.

No presente estudo foram coletados dados básicos sobre o comportamento de Sciurus ingrami em cativeiro, tais como: posturas, ocupação do tempo diário e comportamento sexual, visando assim a embasar estudos da espécie em vida livre.

\section{MATERIAL E MÉTODOS}

O estudo com os serelepes Sciurus ingrami, foram realizados no bosque do Museu de História Natural de Curitiba. O bosque possui uma área de $38.000 \mathrm{~m}^{2}$ com formação vegetacional característica de Floresta Ombrófila Mista a qual encontra-se cercada por muro.

Nesta área está sediado um "criadouro científico" de animais, com espécies silvestres, entre elas Sciurus ingrami, visando ao repovoamento dos parques urbanos do município. Para a manutenção dos serelepes, o criadouro possui cinco recintos, medindo $1 \mathrm{~m}$ de largura, $2 \mathrm{~m}$ de altura e $3 \mathrm{~m}$ de comprimento, revestidos de tela de arame com malha de $2 \mathrm{~cm}$ entre nós. Cada recinto possui internamente diversos galhos e troncos secos, que servem como poleiros e proporcionam aos animais substrato para uma movimentação similar à realizada pelos mesmos na natureza. Como abrigo, existem caixas-ninho acopladas aos viveiros, as quais podem ser retiradas quando necessário, facilitando desta forma o manejo dos animais.

A alimentação dos animais consistia de batata doce, sementes de girassol, ração peletizada para roedores, amendoim com casca, mamão, maçã, bem como sementes nativas de pinhão [Araucaria angustifolia (Bert.) O. Ktze] e coquinhos [Syagrus romanzoffiana (Chamisso) Glassman (Palmae)].

Observações naturalísticas das posturas e comportamentos foram realizadas a uma distância de $10 \mathrm{~m}$ dos recintos, durante vários períodos diários entre outubro de 1994 e novembro de 1995. Foram observados neste período cinco exemplares de Sciurus ingrami (dois machos e três fêmeas) mantidos em recintos isolados. Para as observações adotou-se o método "animal focal" (ALTMANN 1974) e para os registros, um misto de registros funcionais e empíricos (LEHNER 1979).

Inicialmente foram registradas todas as posturas e movimentos dos animais e posteriormente foram selecionados aqueles que se repetiam com maior freqüência. Estas posturas e movimentos foram então descritas detalhadamente, fotografadas e representadas através de esquemas, para a elaboração de um catálogo.

Como os animais encontravam-se cativos há cerca de 10 meses, não apresentavam aparentes distúrbios de comportamento diante da presença humana, não havendo portanto, a necessidade de ocultar-se durante as observações.

Para a quantificação da atividade diária dos animais em cativeiro, foram realizadas sessões periódicas de 10 minutos, para cada um dos animais, totalizando 
50 minutos de observação por dia, ao longo de cinco dias consecutivos em cada estação. Os animais foram observados em horários diferentes, durante os períodos da manhã (06:00 às 11:00 horas) e da tarde (12:00 às 18:00 horas). Cada vez que um comportamento era realizado, após o início da contagem do tempo de observação, este era registrado em uma planilha de quantificação, bem como o tempo dispendido na atividade.

Os dados obtidos foram triados de acordo com quatro categorias de atividades, as quais já haviam sido utilizadas para outros ciurídeos (GURNELL 1987): deslocamento, alimentação, repouso e manutenção. Posteriormente, os dados obtidos para cada uma das categorias foram submetidos a uma análise de freqüência (SOKAL \& ROHLF 1969, ZAR 1984), com o objetivo de verificar uma potencial diferença entre tempo e freqüência de repetições das quatro categorias de comportamento observadas.

Foram também registrados os comportamentos associados à reprodução de dois diferentes casais em recintos isolados mas interligados por tubos de comunicação. Visando a individualizar os animais durante estas observações, os mesmos foram marcados com colares coloridos, semelhantes aos confeccionados por WOOD (1976), possibilitando a identificação de macho e fềmea. Para as observações foram realizadas duas sessões diárias, por um período mínimo de 10 minutos e máximo de 60 minutos em cada sessão. Durante esta fase do estudo, os tubos que interligavam os recintos eram abertos por meio de uma porta de comunicação, permitindo que macho e fềmea mantivessem contato expontaneamente. Nestas sessões foram descritos os comportamentos executados por ambos os sexos individualmente, bem como as interações entre os mesmos.

\section{RESULTADOS}

Foram realizadas um total de 30 horas de observações para o registro das posturas e comportamentos. Ao fim deste período, foi possível descrever quatro posturas principais, as quais são básicas para a compreensão dos demais comportamentos descritos. A partir destas posturas, foi possível registrar alguns comportamentos como: deslocamentos, de manutenção individual, marcação e relacionados ao acasalamento.

\section{Posturas básicas}

Foram identificadas durante as observações, quatro posturas básicas:

\section{Postura em pé}

O serelepe permanece com as quatro patas apoiadas perpendicularmente ao substrato (galho ou piso), ficando o eixo ântero-posterior do animal paralelo e elevado em relação ao substrato. A cauda permanece junto ao dorso, em forma de "S" (Fig. 1a).

\section{Sentado}

Os membros posteriores ficam paralelos ao substrato ao passo que as anteriores formam um ângulo de aproximadamente $45^{\circ} \mathrm{em}$ relação ao mesmo, 
mantendo os cotovelos junto aos joelhos. O dorso do animal permanece curvado, mantendo a região anal próxima ao substrato e às patas posteriores (Fig. 1b), permanecendo a cauda junto ao dorso, em forma de "S". Esta postura possui uma variação, que foi denominada "sentado em duas patas", onde as patas anteriores permanecem elevadas do substrato, ficando junto ao tórax do animal (Fig. 1c), o eixo ântero-posterior do animal forma assim um ângulo de cerca de $60^{\circ} \mathrm{em}$ relação ao substrato, ficando o dorso menos curvado para frente do que na postura sentado descrita anteriormente. Aqui também a cauda permanece junto ao dorso, em forma de "S".

\section{Deitado}

As patas anteriores e posteriores bem como o eixo ântero-posterior do serelepe, permanecem horizontalmente junto ao substrato, a mandíbula fica apoiada sobre as patas anteriores e a cauda estendida linearmente sobre o dorso, ficando a sua porção distal postada sobre a cabeça (Fig. 1d).
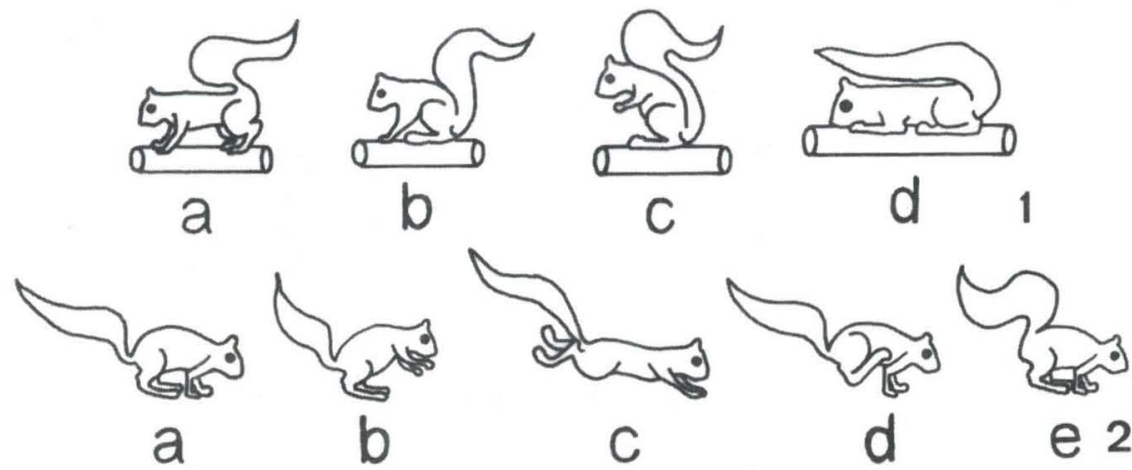

Figs 1-2. (1) Posturas básicas de Sciurus ingrami observadas em cativeiro: em pé (a), sentado (b), sentado em duas patas (c), deitado (d); (2) deslocamento horizontal de S. ingrami: preparação (a), impulso (b), salto (c), queda (d), preparação (e).

\section{Deslocamentos}

Os deslocamentos dos animais em cativeiro, ocorreram sobre diversos tipos de substratos, como a tela de arame dos recintos, galhos e troncos. Foram registradas duas categorias de deslocamento:

\section{Deslocamento horizontal}

Estando na postura em pé, o animal curva o dorso, aproximando as patas anteriores e posteriores (preparação, Fig. 2a). Depois, apoiando-se nas patas posteriores, o animal eleva as patas e a metade anterior do corpo, ficando o eixo ântero-posterior em um ângulo de aproximadamente $45^{\circ}$ em relação ao substrato (Fig. 2b), posteriormente impulsiona o corpo para frente, projetando-se no espaço (salto, Fig. 2c). Durante o salto, há o estiramento do corpo, permanecendo a cauda 
e as patas em uma única direção. Com a queda (Fig. 2d), o animal toca o substrato com as patas anteriores e retorna à preparação (Fig. 2e), podendo ou não reiniciar o deslocamento.

\section{Deslocamento vertical}

Este comportamento pode ser descendente ou ascendente. No descendente, o animal segura-se com as quatro patas lateralmente ao tronco, ficando paralelo a este e com a cabeça voltada para baixo. Os membros posteriores, permanecem estirados para cima e os anteriores perpendiculares ao corpo (Fig. 3a). Partindo desta posição e apoiando-se somente com os membros anteriores, o animal desloca os membros posteriores mais para baixo, junto aos anteriores (Fig. 3b), em seguida num movimento único, desloca os membros anteriores para baixo, resultando no deslocamento do corpo para baixo (Fig. 3c).

De forma semelhante ao descrito anteriormente, no deslocamento vertical ascendente, $\mathrm{o}$ animal segura-se com as quatro patas dispostas lateralmente ao tronco, com os membros anteriores perpendiculares ao eixo do corpo e a cabeça voltada para cima. Em seguida, apoiando-se nos membros anteriores, desloca os posteriores para cima aproximando-os dos anteriores. Suportado agora pelos membros posteriores, desloca os membros anteriores para cima, num movimento único, deslocando o corpo.

Um comportamento muito associado a estes deslocamentos verticais, ocorria quando o serelepe sentia-se sob ameaça. Nesta ocasião o animal posicionava-se rapidamente atrás de um tronco vertical, mantendo-se na postura inicial apresentada no deslocamento vertical ascendente.
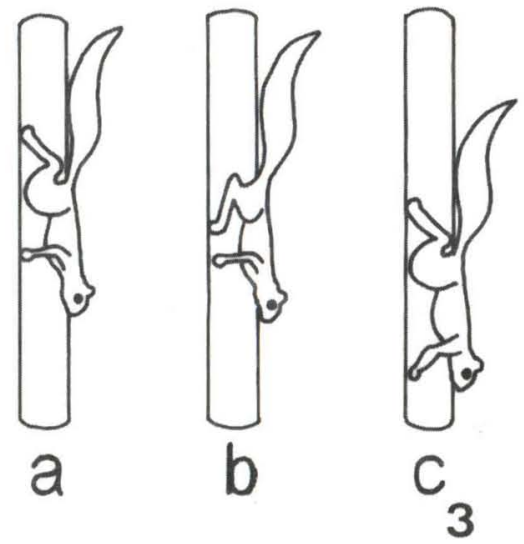

Fig. 3. Seqüência de deslocamento vertical descendente de $S$. ingrami. Posição inicial (a), deslocamento das patas posteriores (b), deslocamento do corpo (c).

\section{Comportamentos de manutenção}

Foram relacionados nesta categoria quatro comportamentos de coçar o corpo e dois de espreguiçamento, os quais são executados de diferentes formas e em diferentes posições, visando a "limpeza" corporal e relaxamento do animal. 


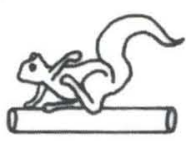

a

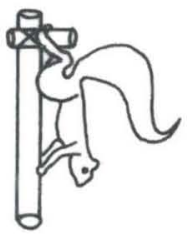

a

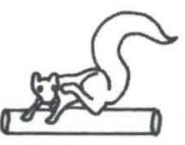

b

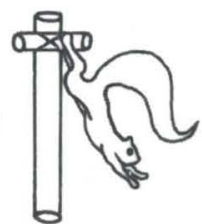

b

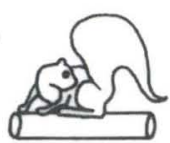

C

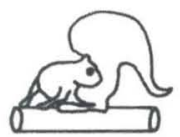

d

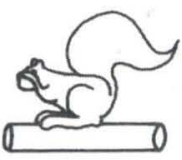

e
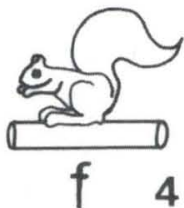

Figs 4-5. (4) Comportamentos de manutenção individual de S. ingrami: coçar as axilas (a), coçar a cabeça (b), coçar o dorso (c), coçar a cauda (d), coçar o focinho (e, f); (5) seqüência do comportamento de espreguiçar apresentada por $S$. ingrami: de cabeça para baixo $(a, b) e$ em pé $(c, d, e)$.

\section{Coçar as axilas}

$\mathrm{O}$ animal estando na postura sentado, move um dos membros anteriores lateralmente para cima e atrita a região axilar com a pata posterior do mesmo lado (Fig. 4a).

\section{Coçar a cabeça}

Estando na postura sentado e mantendo as duas patas anteriores apoiadas no substrato, o animal movimenta uma das patas posteriores em direção à cabeça, atritando-a contra a orelha e nuca (Fig. 4b).

\section{Coçar as costas e cauda}

Partindo da postura sentado, o animal realiza uma torção lateral em direção ao dorso, aproximando o focinho da região lombar, nesta posição, começa a mordiscar as costas (Fig. 4c) e/ou a base da cauda (Fig. 4d).

\section{Coçar o focinho}

$\mathrm{Na}$ postura sentado em duas patas, o esquilo movimenta as patas anteriores paralelamente à cabeça, no sentido circular dos olhos para o focinho, repetidamente (Fig. 4e,f).

\section{Espreguiçar de cabeça para baixo}

Com a cabeça para baixo, apoiando-se com as patas posteriores em um galho horizontal e as anteriores em um tronco vertical (Fig. 5a), o esquilo afasta as patas anteriores do substrato, curvando as costas para trás e para cima, balançando-se por alguns segundos (Fig. 5b), a cauda geralmente fica curvada para baixo, em forma de "s". 


\section{Espreguiçar em pé}

$\mathrm{O}$ animal estando de frente a um tronco vertical, na postura sentado sobre duas patas (Fig. 5c), apoia as patas anteriores no tronco e deslocando-as para cima, estira o corpo sem no entanto mover as patas posteriores (Fig. 5d). Durante este estiramento, há o encurvamento da coluna vertebral para trás. O estiramento do corpo pode ser seguido pelo estiramento das patas posteriores (Fig. 5e).
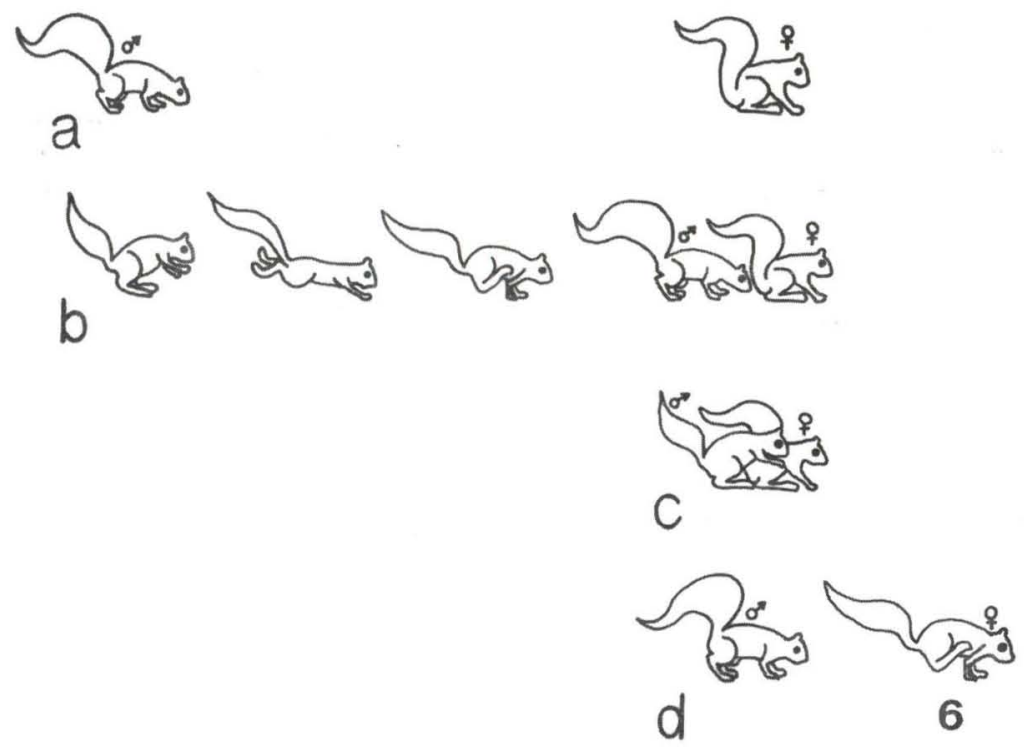

Fig. 6. Representaçào do comportamento exploratório e de cópula: inicialmente o macho explora o ambiente por onde a fêmea passou (a), ao aproximar-se da fêmea, cheira a sua região genital (b), tentando posteriormente a cópula (c), mas a fêmea pode esquivar-se e iniciar a fuga (d).

\section{Comportamento reprodutivo}

Durante os meses de dezembro de 1994 e março de 1995, foram realizadas um total de 30 horas de observações sobre o comportamento reprodutivo de $S$. ingrami, com 14 registros de interação entre macho e fêmea (dois casais).

Os comportamentos apresentados pelos machos e associados à reprodução, dividiram-se em duas fases distintas: a primeira corresponde ao comportamento exploratório, que podia ser do ambiente e da fềmea e a segunda, ao comportamento de perseguição e tentativa de cópula.

No comportamento exploratório, o macho cheirava os vários locais por onde a fêmea havia estado parada ou de passagem (Fig. 6 a), deslocando-se lentamente. Algumas vezes a fêmea permitia a aproximação do macho, nestas ocasiões, o macho estirava o pescoço (Fig. 6b) e cheirava por alguns segundos a genitália da fêmea (comportamento exploratório da fêmea). Ela em seguida afastava-se e o macho voltava a explorar o ambiente. Após algum tempo cheirando o caminho percorrido 
pela fêmea, o macho ia ao encontro da mesma, procurando aproximar-se. Em algumas das aproximações para cheirar a genitália da fêmea, o macho tentava contê-la pela região posterior (Fig. 6c), no entanto estas tentativas não obtiveram aparente sucesso, pois ela rapidamente esquivava-se e fugia (Fig. 6d). Após a esquiva da fềmea, o macho iniciava a perseguição da mesma, por um período curto de tempo. Durante as aproximações para cheirar a genitália da fềmea, o macho agitava a cauda, de um lado para outro.

Durante as observações, identificou-se também um comportamento realizado principalmente durante as interações entre os animais e após a alimentação, citado na literatura como "face-wipping" (TAYLOR 1977) ou "marcação facial", que era realizado da seguinte forma: a partir da postura sentado (Fig. 7a), o esquilo passa a deitado (Fig. 7b). Em seguida desloca-se para frente, atritando alternadamente cada um dos lados da face contra o galho (Fig. 7c,d). Durante a execução deste comportamento, o animal sempre se mantém junto ao galho.

Em algumas perseguições, quando macho e fềmea posicionavam-se frente a frente por alguns segundos, ambos aproximavam seus focinhos e cheiravam um ao outro. Depois num movimento rápido a fêmea saltava sobre o macho ou virava no sentido oposto afastando-se dele. Nesta ocasião a perseguição era reiniciada. Constatou-se durante as observações, que de maneira geral, a fêmea evitava o contato com o macho, porém às vezes, ela aproximava-se dele num salto único e fugia rapidamente, provocando a perseguição.

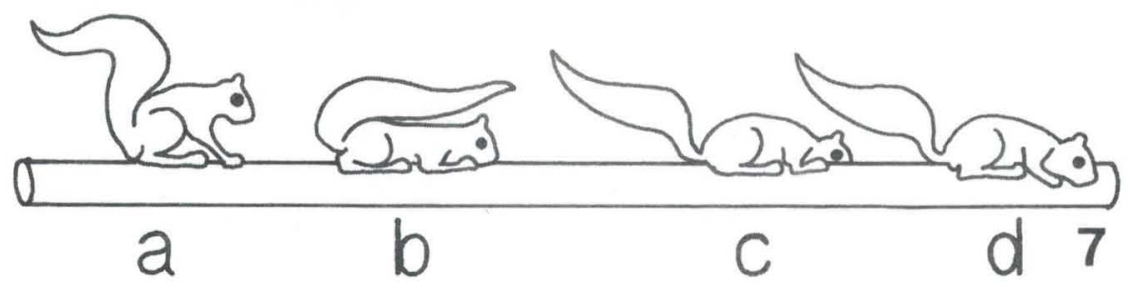

Fig. 7. Seqüência do comportamento de marcação, apresentada por S. ingrami. sentado (a), deitado (b), deslocamento (c, d).

\section{Atividade diária}

Com base nas observações dos comportamentos realizados em cativeiro, as atividades dos esquilos foram divididas em quatro grandes categorias comportamentais, caracterizadas da seguinte forma:

\section{Repouso ou atividade de descanso}

É caracterizada pelas posturas sentado e deitado, onde o animal não realiza qualquer deslocamento. Os períodos em que os serelepes encontravam-se no interior da caixa-ninho, foram também considerados como repouso. 


\section{Deslocamento}

Caracterizados pelos dois tipos de deslocamentos anteriormente descritos, vertical (ascendente e descendente) e horizontal.

Manutenção: caracterizada por todas as seqüências comportamentais de espreguiçar e coçar.

\section{Alimentação}

Esta atividade é caracterizada por duas posturas principais: a básica, a partir da qual o animal procura e pega o alimento, e a postura sentado em duas patas, utilizada quando o animal permanece estacionado, para comer o alimento, manipulando-o com as patas anteriores.

Das quatro atividades diárias, a que mais foi executada pelos serelepes e também a que ocupou a maior parte do tempo dos animais foi a de deslocamento (Figs. 8, 9).

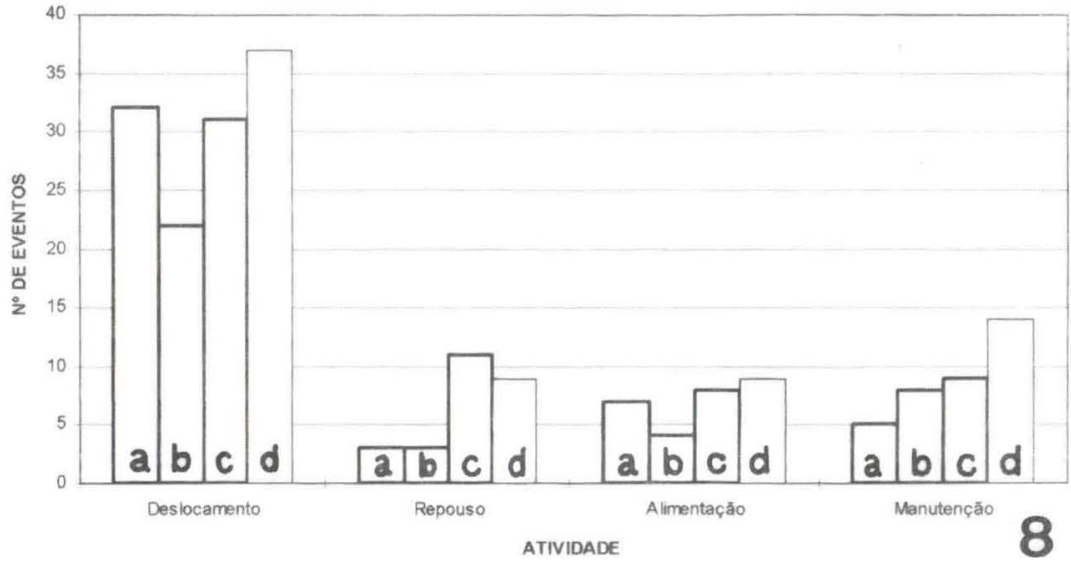

Fig. 8. Atividade diária de $S$. ingrami em cativeiro, com relaçăo à quantidade de vezes que a atividade foi executada, durante 10 minutos de observação.

Com base nas figuras 8 e 9, é possível verificar que a atividade de deslocamento mostrou também uma relação de equivalência, entre o tempo dispendido e o número de deslocamentos realizados, para cada estação do ano. Outro aspecto verificado é que correu uma variação sazonal nesta atividade, a qual decresceu durante o inverno e aumentou durante a primavera e verão.

Já a atividade de repouso mostrou variação entre o tempo dispendido e o número de eventos realizados ao longo das estações, pois apesar de ter sido realizada poucas vezes, o tempo ocupado pela mesma foi relativamente grande. Sazonalmente esta variação mostrou-se mais aparente onde, apesar de no outono e inverno esta atividade ter sido realizada de forma semelhante, $\mathrm{o}$ tempo gasto em cada estação foi diferente, tendo os animais permanecido mais tempo repousando no inverno que durante o outono. Durante o inverno, os animais mostraram-se mais ativos no período da manhã, recolhendo-se às suas caixas-ninho após as 16:00 horas. Após o inverno, o tempo gasto com esta atividade começou a diminuir (Fig. 9). 


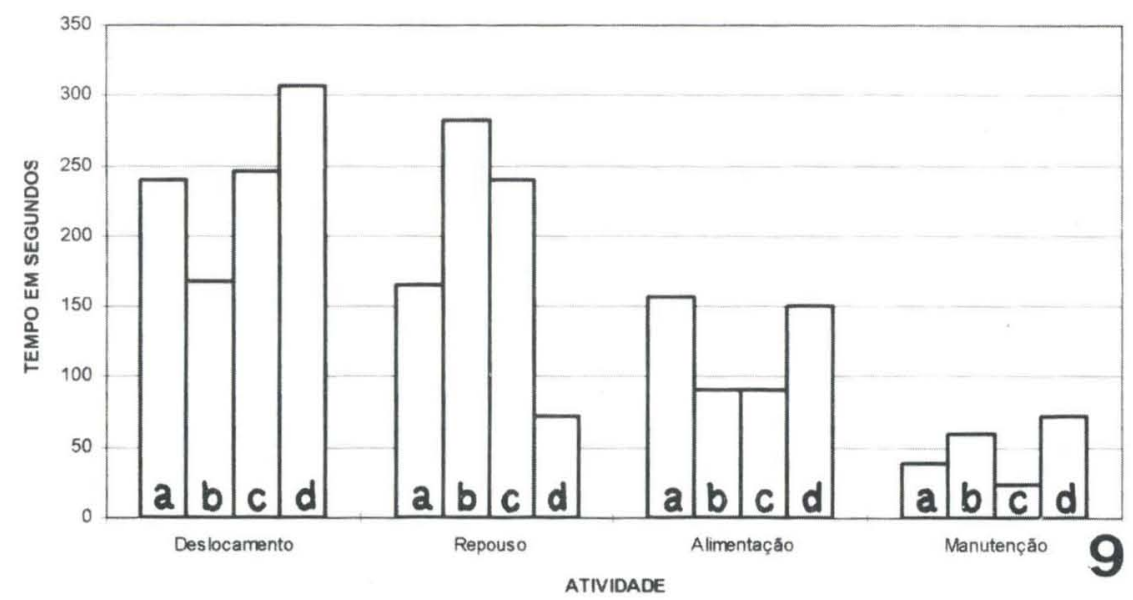

Fig. 9. Atividade diária de $S$. ingrami em cativeiro, com relação ao tempo dispendido em cada atividade, durante 10 minutos de observação.

A atividade de alimentação, com relação ao número de eventos realizados, apresentou pouca variação ao longo das estações do ano (Fig. 8). Por outro lado, com relação ao tempo dispendido, os animais gastaram mais tempo alimentando-se no outono e verão, que durante o inverno e primavera (Fig. 9).

Quanto à atividade de manutenção, houve um aumento crescente no número de eventos realizados ao longo das estações (Fig. 8) contudo, o tempo gasto na sua execução foi muito variado (Fig. 9).

Através da utilização de tabelas de contingência para comparar a freqüência do número de eventos realizados em cada comportamento ao longo das estações do ano, foi verificado que não houve diferença significativa quanto à quantidade de vezes em que os animais realizaram cada atividade em cada estação do ano ( $\mathrm{X}^{2}$ $=10,973 ;$ G.L. $=9 ; 0,30<\mathrm{P}<0,20)$.

Por outro lado, a comparação entre a atividade de deslocamento e as demais atividades, nas quatro estações estudadas quanto ao número de eventos, demonstrou que a quantidade de vezes em que os animais deslocaram-se em cativeiro foi significativamente maior do que as demais atividades, em todas as estações (Tab. I).

Já com relação ao tempo dispendido em cada atividade, a tabela de contingência feita para os dados contidos na Figura 9, demonstrou que existe uma variação significativa entre as estações do ano quanto ao tempo gasto em cada atividade $\left(\mathrm{X}^{2}=217,425 ;\right.$ G.L. $\left.=9 ; \mathrm{P}<0,001\right)$.

\section{DISCUSSÃO}

\section{Posturas e deslocamentos}

As posturas e deslocamentos apresentados por Sciurus ingrami no presente estudo, mostraram ser similares à outras já descritas para os demais ciurídeos, como por exemplo S. carolinensis e S. niger (BENSON 1980). 
Tabela I. Valores do teste $\mathrm{X}^{2}$ obtidos na comparação da atividade de deslocamento de $S$. ingrami em relação às demais atividades, nas quatro estações do ano: deslocamento (1), alimentação (2), manutenção (3), repouso (4). * valores significativos para $\alpha=0,05$ e G.L.=1.

\begin{tabular}{lcccc}
\hline Estação & Comparação & Valor $X^{2}{ }^{*}$ & Comparação & Valor $\mathrm{X}^{2}$ \\
\hline Primavera & $1 \times 2 \times 3 \times 4$ & 24,184 & $2 \times 3 \times 4$ & 0,489 \\
Verão & $1 \times 2 \times 3 \times 4$ & 31,112 & $2 \times 3 \times 4$ & 1,562 \\
Outono & $1 \times 2 \times 3 \times 4$ & 47,190 & $2 \times 3 \times 4$ & 1,600 \\
Inverno & $1 \times 2 \times 3 \times 4$ & 24,928 & $2 \times 3 \times 4$ & 3,400 \\
\hline
\end{tabular}

A forma esguia do corpo, os membros posteriores longos e a cauda, tornam os esquilos animais bem adaptados à vida arborícola (GURNELL 1987), deslocandose com grande agilidade e segurança entre os galhos de árvores. Este aspecto foi também constatado em cativeiro, onde $S$. ingrami deslocou-se com rapidez por entre os galhos do viveiro, apesar do pequeno espaço disponível.

HOR WICH (1972) estudando o comportamento de S. carolinensis em cativeiro e THOMPSON (1977a) em vida livre, verificaram que estes esquilos utilizam-se da postura sentado ao sentirem-se sob ameaça, sendo este comportamento denominado por THOMPSON (1977a) de "postura de atenção", dado ao contexto em que se encontrava. FAJARDO PATIÑO \& DE LA OSSA (1989) também verificaram este mesmo comportamento para $S$. granatensis em Barro Colorado (Panamá) e destacaram ainda, que a cauda dos esquilos serve para facilitar a ocultação no ambiente.

Em cativeiro, S. ingrami não apresentou comportamentos do tipo "postura de atenção", como os descritos para S. carolinensis e S. granatensis, o que pode estar relacionado à ambientação com o cativeiro e a ausência de potenciais predadores. Por outro lado, os animais em presença de estranhos assumiam um comportamento similar à "postura de atenção", mas ao invés de permanecerem sentados, ocultavam-se atrás de um tronco, permanecendo estáticos segurando-se no sentido vertical. Este comportamento também mostrou-se similar ao descrito para outros ciurídeos (GURNELL 1987).

A capacidade de poder permanecer na postura sentado, permite ao serelepe, manter os membros anteriores livres para manipulação de alimento. Este aspecto parece ser essencial no consumo de sementes, principalmente daquelas que possuem endocarpo lignificado, pois obrigam o animal a segurar a semente para poder abri-la, conforme já foi descrito por BORDIGNON et al. (1996).

A utilização da cauda para a ocultação, parece ter o objetivo de diminuir ilusoriamente o tamanho dos esquilos impedindo ao observador e conseqüentemente a um potencial predador, a delimitação do contorno do corpo, que aliado ao seu comportamento estático, o torna quase imperceptivel no ambiente. Neste sentido, a ocultação do corpo com a cauda, parece ser utilizado não somente durante os períodos de alimentação, mas também durante o descanso e manutenção, para ajudar na ocultação no ambiente.

A postura "deitado" foi realizada por $S$. ingrami sempre em dias de temperatura elevada, durante o período das 12 às 14 horas, e foi semelhante à descrita para S. carolinensis por BAKKEN (1959). VILJOEN (1985) sugere que os esquilos utilizam-na como alternativa para a termorregulação corporal, em dias de temperatura 
elevada. MUCHLINSKI \& SHUMP (1979) sugerem que a cauda dos esquilos auxilia o animal à diminuir a temperatura corporal em dias quentes, aumentando a superfície corporal em contato com o ar e com isso liberando mais calor ao ambiente. Da mesma forma, em dias de muito frio, ao sentar-se e posicionar a cauda sobre o dorso, o animal cria uma área de isolamento térmico na parte dorsal do corpo, diminuindo a perda do calor para o ambiente.

\section{Comportamentos}

Os comportamentos de manutenção, registrados durante o estudo, mostraram ser diversificados, embora semelhantes aos descritos para $S$. carolinensis (ThOMPSON 1977a), S. niger (GuRNELl 1987) e S. vulgaris (Holm 1994).

Os comportamentos de "coçar" realizados pelos serelepes, certamente fazem parte de um comportamento de manutenção básico, denominado por MCCLOSKEY \& SHAW (1977) de "grooming", sendo este tipo de comportamento, realizado também pelos esquilos após a cópula entre macho e fêmea (KOPROWSKI 1992).

Apesar dos comportamentos e posturas dos ciurídeos já serem bem conhecidos, principalmente os do Hemisfério Norte, não foram encontradas na literatura referências semelhantes ao comportamento de "espreguiçar" executado pelos serelepes em cativeiro (Fig. 5). Este comportamento parece estar relacionado com a necessidade destes animais, em manterem sua elasticidade corporal, para poderem executar os diversos deslocamentos por entre galhos e troncos. No entanto, provavelmente devido à grande atividade dos esquilos na natureza o comportamento de espreguiçar pode ter uma freqüência muito baixa, não sendo por isso detectado nas amostragens de campo.

O comportamento de "marcação" observado em S. ingrami é, segundo a literatura um comportamento comum entre os ciurídeos, como por exemplo $S$. carolinensis (TAYLOR 1977) e S. niger (KOPROWSKI 1993), sendo denominada de "face-wiping". Durante o comportamento de marcação, os animais utilizam uma secreção produzidas em glândulas localizadas na região oral-labial, para marcar os galhos por onde passam. Segundo GURNELL (1987) a marcação facial é utilizada pelos esquilos no reconhecimento do status social dos indivíduos, como no caso de S. niger. Apesar disto, os esquilos podem utilizar também a urina para marcar seus limites individuais, seja em árvores ou no solo (HORWICH 1972; LAIDLER 1980). Durante o estudo, os serelepes urinaram em vários locais nos viveiros (obs. pess.), mas não foi possível determinar se este comportamento tinha influência nas interações entre macho e fêmea.

\section{Comportamento reprodutivo}

Os comportamentos relacionados à reprodução, observados para S. ingrami, foram semelhantes aos de S. carolinensis (THOMPSON 1977a), S. niger (MCClOSKEY \& SHAW 1977), S. aberti (FARENTINOS 1972), Tamiasciurus hudsonicus (LAYNE 1954) e de $S$. vulgaris (WAUTERS \& DHONDT 1989).

THOMPSON (1977a) dividiu o comportamento sexual de $S$. carolinensis em quatro fases distintas: pré-perseguição, perseguição de acasalamento, cópula e pós-cópula. No presente estudo, os machos de S. ingrami realizaram apenas as duas 
primeiras fases: o comportamento de seguir a pista da fêmea (pré-perseguição) e o comportamento de perseguir a fêmea.

O comportamento de seguir a fêmea, observado nos machos de $S$. ingrami em cativeiro, é denominado por THOMPSON (1977a) de "trilha sexual" (sexual trailing), na qual os machos localizam a fềmea durante o período de estro, seguindo a trilha de odores deixada pela mesma, através da urina, em vários locais por onde passa. Este mesmo comportamento é citado para outros ciurideos, como: $S$. aberti (FARENTINOS 1972) e S. niger rufiventer (MCCLOSKEY \& SHAW 1977). O comportamento de cheirar a genitália da fêmea, coincidiu com o já descrito para $S$. carolinensis como "genital sniffs" (THOMPSON 1977a), este comportamento segundo GURNELL (1987) serve para que o macho possa avaliar o estado receptivo da fêmea durante o estro. O comportamento de marcação facial, observado para $S$. ingrami, por estar relacionado à marcação territorial dos esquilos (GURNELL 1987), provavelmente tem alguma influência no comportamento reprodutivo.

De acordo com THOMPSON (1977a), durante as perseguições de acasalamento, podem ocorrer confrontos agonísticos entre os machos participantes e também entre estes e a fêmea no estro. Entretanto, o fato de não terem sido registrados comportamentos agonísticos para $S$. ingrami durante as observações em cativeiro, deve-se provavelmente à falta de outros machos nas interações entre os animais cativos. THOMPSON (1977a) observou também, que durante a perseguição da fêmea por vários machos, ocorriam não só lutas entre os machos, pela liderança na fila de perseguição, como confrontos entre a fêmea e os machos perseguidores. Aquele autor, relata ainda que para $S$. carolinensis, o fato dos machos perseguidores lutarem entre si pela liderança da fila, durante a perseguição de acasalamento, parece estimular a fêmea em estro à cópula. Assim, a ausência de confrontos entre machos de $S$. ingrami em cativeiro, deve portanto diminuir a escitabilidade dos indivíduos, diminuindo a intensidade dos encontros entre machos e fêmeas. Esta também deve ser a provável explicação de não ter sido observado cópula durante o período de estudo, apesar das tentativas feitas pelos machos.

WEBLEY \& JONHSON (1983) sugerem que a reprodução dos esquilos em cativeiro, pode ser dificultada por fatores como espaço dos recintos e o período de adaptação dos animais ao novo ambiente, entretanto, estes problemas parecem não ter sido tão marcantes para $S$. ingrami, pois após o período de observações, durante o mês de dezembro de 1995, ocorreu o nascimento de três fillhotes de serelepes no "criadouro científico" do Museu de História Natural Capão da Imbuia (R.R. Lange e T.C.C. Margarido comunicação pessoal). Isto demostra que o sistema de tubos de ligação para aproximar macho e fềmea, funcionou satisfatoriamente durante o estudo, possibilitando aos animais visitarem-se livremente mantendo-se ao mesmo tempo a individualidade dos recintos.

\section{Atividade diária}

A atividade diária dos esquilos é determinada, assim como para muitos mamíferos, pelas condições ambientais (GURNEL 1987).

A maioria dos esquilos do Hemisfério Norte possuem dois picos de atividade 
diária, no início da manhã e no fim da tarde, com exceção do período de inverno, quando apresentam um único pico ao meio do dia (THOMPSON 1977b; LARSON 1986). Em cativeiro porém, como a oferta de alimento é constante e a competição intra e interespecífica não ocorre, a atividade dos animais é geralmente influenciada apenas pela temperatura e período luminoso (HoRWICH 1972).

A atividade de deslocamento mostrou uma diminuição no tempo dispendido no inverno, provavelmente devido ao aumento no tempo ocupado na atividade de repouso, pois durante o inverno os serelepes permaneciam mais tempo no interior de seus ninhos ou sentados com a cauda posicionada sobre o dorso. Este comportamento está relacionado, com a necessidade de manter o calor corporal, contendo o gasto energético em épocas de temperaturas muito baixas, como ocorre com os esquilos das regiões temperadas (GURNELL 1987).

Desta forma, a diferença aparente entre tempo gasto $/ \mathrm{n}^{\circ}$ de vezes, na realização da atividade de repouso, verificada neste estudo (Figs 8, 9), deve-se provavelmente à esta regulação térmica realizada pelos esquilos.

Já durante as estações quentes, verificamos que os serelepes executavam com maior freqüência a postura deitado. Isto ocorre provavelmente porque com o aumento do calor corporal por influência do ambiente, os animais são obrigados a repousar. Tal postura, associada à manutenção da cauda estendida, já foi relacionada à perda de calor para o meio, em estudos realizados com outros esquilos, como por exemplo: Sciurus niger e Tamiasciurus hudsonicus (MUCHLINSKI \& SHUMP 1979) e $S$. carolinensis (HoLm 1994).

O aumento no tempo gasto com alimentação, apresentado por S. ingrami, tanto no outono quanto no verão e sua diminuição durante o inverno e primavera, pode estar relacionado à potencial preferência quanto ao alimento oferecido. Durante $o$ outono quando eram oferecidos pinhões (Araucaria angustifolia), os animais aparentavam preferi-los à outros alimentos, como amendoim, batata doce, mamão e maçã além de ração para roedores. No entanto, o tempo gasto com alimentação durante o outono, pode também estar relacionado à necessidade de armazenamento de calorias, as quais são utilizadas durante períodos de escassez de alimentos, como ocorre em populações selvagens de esquilos (GURNELL 1987; Holm 1994). Mesmo não necessitando utilizar-se desta estratégia, pois a oferta de alimento em cativeiro é constante, esta atividade deve ser mantida como resposta a uma estratégia evolutivamente adaptada à condições naturais.

Esta aparente preferência por determinado alimento, era apresentada também para os frutos de Syagrus romanzoffiana (coquinhos) oferecidos durante o verão. Conseqüentemente por necessitarem de mais tempo para abrir os coquinhos, através de cortes com os dentes incisivos (BORDIGNON et al., no prelo), os animais gastavam mais tempo alimentando-se nesta estação.

Ao longo do presente estudo, as observações sobre o comportamento de $S$. ingrami, evidenciaram a dificuldade em se realizar um plano de manejo e reprodução desta espécie em cativeiro, demonstrando o quanto é necessário o estudo do comportamento animal, visando a compreensão do modo de vida de determinadas espécies, mas de forma positiva, o estudo e observação do comportamento dos 
esquilos em cativeiro, deverá auxiliar muito o acompanhamento futuro de populações nativas destes animais.

AGRADECIMENTOS. Ao CNPq pela bolsa de mestrado entre os anos de 1994 e 1996, ao Curso de Pós-graduação em Zoologia, Universidade Federal do Paraná; à Tereza Cristina Castellano Margarido e Rogério Ribas Lange (Prefeitura Municipal de Curitiba) pelo apoio, à Fundação "O Boticário de Proteção à Natureza" e à Diretoria do Parque Recreativo Primavera.

\section{REFERÊNCIAS BIBLIOGRÁFICAS}

ALtMANN, J. 1974. Observational Study of Behavior: Sampling Methods Behavior 49: 227-265.

BAKKen, A. 1959. Behaviour of gray squirrels. Proc. Ann. Conf. S.E. Assoc. Game \& Fish Comm. 13: 393-406.

BENSON, B.N. 1980. Dominance relationships, mating behaviour and scent marking in fox squirrels (Sciurus niger). Mammalia 44: 143-160.

Bordignon, M.; T.C.C. Margarido \& R.R. LAnge. (no prelo). Formas de abertura dos frutos de Syagrus romanzoffiana (Chamisso) Glassman efetuadas por Sciurus ingrami Thomas, 1901 (Rodentia, Sciuridae). Revta bras. Zool.

EMMONS, L.H. 1990. Neotropical Rainforest Mammals: a Field Guide. Chicago USA, The University of Chicago Press, 290p.

FAJARDO PATIÑO, A. \& V. DE LA OSSA. 1989. Apuntes etoecologicos sobre Sciurus granatensis gerrardi (Rodentia: Sciuridae) en los Montes de Maria y Serrania de Coraza (Sucre, Colombia). Trianea, Act. Cient. Tecn., Iderena, 3: 173-182.

FARENTINOS, R.C. 1972. Social dominance and mating activity in the tassel-eared squirrel (Sciurus aberti ferreus). Anim. Behav. 20 (2): 316-326.

FisCHER, R.A. \& N.R. HolLER. 1991. Habitat use and relative abundance of gray squirrels in Southern Alabama. Jour. Wildl. Manage. 1991. 55 (1): 52-58.

Galetti, M.; M. Paschoal \& F. Pedroni. 1992. Predation on palm nuts (Syagrus romanzoffiana) by squirrels (Sciurus ingrami) in south-east Brazil. Jour Trop. Ecol. 8: 121-123.

GuRNelL, J. 1987. The natural history of squirrels. London, Christopher Helm Ltd., $201 \mathrm{p}$.

Holm, J. 1994. Squirrels. London, Whittet Books, 127p.

HoRWICH, R.H. 1972. The ontogeny of social behavior in the gray squirrel (Sciurus carolinensis). Adv. in Ethol. 8: 1-103.

KoPROWSKI, J.L. 1992. Removal of copulatory plugs by female tree squirrels. Jour. Mamm. 73 (3): 572-576.

1993. Behavioral tactics, dominance, and copulatory succes among male fox squirrels. Ethol. Ecol. \& Evol. 5: 169-176.

LAIDLER, K. 1980. Squirrels in Britain. London, Newton Abot Ed., 232p.

LARSON, E.A. 1986. Merriam's chipmunk on Palo Escrito in the Santa Lucia Mountains of California. Part II. The individual in relation to its enviroment with recorded episodes of naturalistic behavior. Big Pine, California, Waucoba 
Press, $361 \mathrm{p}$.

LAYNE, J.N. 1954. The biology of the red squirrel, Tamiasciurus hudsonicus loquax (Bangs), in central New York. Ecol. Mono. 24: 227-267.

LEHNER, P.N. 1979. Handbook of Ethological Methods. New York, Garland STPM Press, 430p.

McCloskeI, R.J. \& K.C. SHAw. 1977. Copulatory behavior of the fox squirrel. Jour. Mamm. 58: 663-665.

MUCHLINSKI, A.E. \& K.A. SHUMP. 1979. The Sciurid tail: a possible thermoregulatory mechanism. Jour. Mamm. 60 (3): 652-654.

PASITSCHNIAK-ARTS, M. \& J.F. BENDELL. 1990. Behavioural differences between locally recruiting and dispersing gray squirrels, Sciurus carolinensis. Can. Jour. Zool. 68: 935-941.

RIEGE, D.A. 1991. Habitat specialization and social factors in distribution of red and gray squirrels. Jour. Mamm. 72: 152-162.

SoKal, R.R. \& F.J. RoHLF. 1969. Biometria, Princípios y métodos estadísticos en la investigación biológica. Madri, H. Brume Ed., 832p.

TAYLOR, J.C. 1977. The frequency of grey squirrel (Sciurus carolinensis) communication by use of scent marking points. Jour. Zool., London, 183: 543-545.

ThOMPSON, D.C. 1977a.Reproductive behavior of the grey squirrel. Can. Jour. Zool. 55: 1176-1184.

. 1977b. Diurnal and seasonal activity of the grey squirrel (Sciurus carolinensis). Can. Jour. Zool. 55: 1185-1189.

Tinbergen, N. 1966. Animal Behavior. London, Time Inc. Ed., 179p.

VILJOEN, S. 1985. Comparative thermoregulatory adaptations of Southern African tree squirrels from four different habitats. S. African Jour. Zool. 20: 28-32.

WAUters, L. \& A.A. DhonT. 1989. Body weight, longevity and reproductive success in red squirrels (Sciurus vulgaris). Jour. Anim. Ecol. 58: 637-651.

WeBLEY, G. E. \& E. JONHSON, E. 1983. Reproductive physiology of the grey squirrel (Sciurus carolinensis). Mamm. Rev. 13: 149-154.

WooD, D. A. 1976. Squirrel collars. Jour. Zool., London, 180: 513-516.

ZAR, J.H. 1984. Bioestatistical Analysis. New Jersey, Prentice-Hall International Inc., $2^{\text {nd }}$ ed., $718 \mathrm{p}$.

Recebido em 16.I.1997; aceito em 10.IX.1997. 